${ }^{\odot}$ Entomologica Fennica. Vol. 1:189. 3.XII.1990

\title{
Response of parasitoids of the genus Peristenus Förster (Hymenoptera, Braconidae) to temperature changes during the diapause
}

\author{
Teresa Bilewicz-Pawińska \\ Institute of Ecology, Polish Academy of Sciences, Dziekanów Leśny near Warsaw, 05-092 Łomianki, \\ Poland
}

\author{
Anna-Liisa Varis \\ Department of Agricultural and Forest Zoology, University of Helsinki, SF-00710 Helsinki, Finland
}

The braconids of the genus Peristenus Förster are common parasitoids of the Miridae species, both in North America (Loan 1965, Clancy \& Pierce 1966) and in Europe (Loan \& Bilewicz-Pawińska 1973, Bilewicz-Pawińska 1982). Peristenus species develop from the egg stage to the fifth larval stage in the host insect, then leave the host and pupate in the soil. In Poland the pupal stage lasts from 8 to 10 months (Bilewicz-Pawińska 1982).

The aim of the present study was to investigate the response of overwintering braconids to temperature variations. This information is needed for storing and transport of pupae for possible use in biological control.

\section{Materials and methods}

Five Peristenus-species were used for the investigations:

$P$. rubricollis Thomson, $P$. digoneutis Loan, $P$. stygicus Loan, $P$. stenodemae Loan and $P$. pallipes (Curtis). A total of more than 600 Peristenus specimens consisting of an equal number of each species were used for experiments. The parasitoids had pupated in the soil from mirids collected in rye fields. Cocoons were put in small cages and kept from October to April in a refrigerator at a mean temperature of $4.5^{\circ} \mathrm{C}$ and $65 \%$ RH. During the period between the fourth and seventh month of cold storage a random sample of 25 cocoons was transferred every 30 th day to a higher temperature of approximately $22^{\circ} \mathrm{C}$. RH was the same the whole time. After four months storage, two series of experiments were done: half the cocoons were maintained in complete darkness, half exposed to natural daylight conditions.

\section{Results and conclusions}

The cocoons kept in darkness and those kept in natural daylight conditions showed no difference in the emerging time after the temperature was raised. For each species, the minimum time needed to interrupt the diapause was at least 2.5-3.5 months, keeping the cocoons at a low temperature. When the temperature was raised earlier the insects died (cf. Bilewicz-Pawińska 1977). On the other hand, it is known from an other study (Bilewicz-Pawińska, unpublished) that temperatures below zero (mean $-7^{\circ} \mathrm{C}$, range from -5 to $-11^{\circ} \mathrm{C}$ ) lasting one month affected the life span of the parasitoids positively.

For the same storage duration, the investigated species reacted differently when the temperature was raised (Fig. 1). In all species, however, the termination of the diapause and the emergence of the parasitoids, both started earlier when the diapause had lasted longer. 


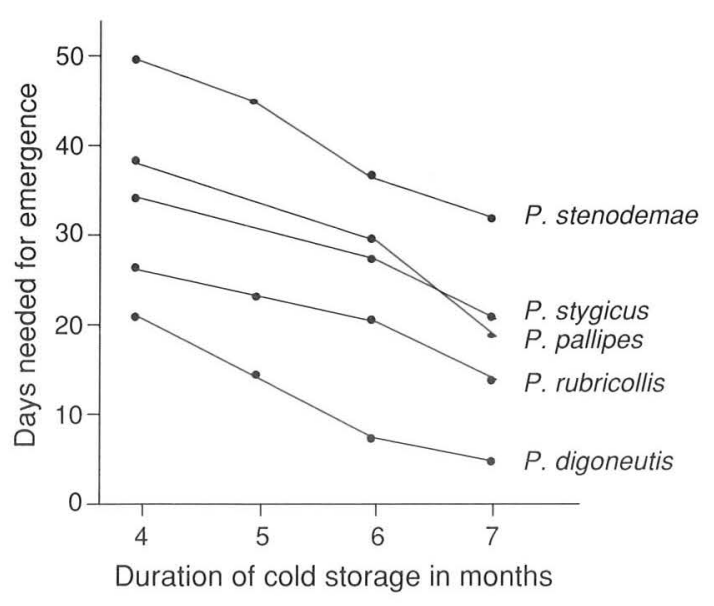

Fig. 1. Effect of length of cold storage on the emergence of Peristenus cocoons: average number of days needed for emergence after transfer to higher temperature (average $+22^{\circ} \mathrm{C}$ ).

The termination of diapause depends on the optimum temperature which is needed for diapause development (cf. Lees 1956). In our experiments, the species most sensitive to the variations in the temperature during the diapause were $P$. digoneutis and $P$. rubricollis (Fig. 1), which also had the lowest optimum temperatures. Compared with other species, $P$. stenodemae had the greatest temperature range. $P$. pallipes and $P$. stygicus were intermediate. It seems that the species with lower optimum temperature originate from a colder climate and those with higher optimum temperature from a warmer climate (cf. Lees 1956). When Peristenus-species are used for biological control, special care (in storing and transport) must be taken of the species with lower optimum temperatures and with higher sensitivity to temperature variations.

\section{References}

Bilewicz-Pawińska, T. 1977: Time reduction of diapause of parasitic Peristenus Foerster (Hymenoptera) under laboratory conditions. - Bull. Acad. Polon. Sci. Sèr. Sci. Biol. 25(5):301-305.

- 1982: Plant bugs (Heteroptera, Miridae) and their parasitoids (Hymenoptera, Braconidae) on cereal crops. Pol. Ecol. Stud. 8(1-2): 113-191.

Clancy, D. W. \& Pierce, H. D. 1966: Natural enemies of some Lygus bugs. - J. Econ. Entomol. 59(4):853-858.

Lees, A. D. 1956: The physiology and biochemistry of diapause. - Ann. Rev. Entomol. 1:1-16.

Loan, C. C. 1965: Life cycle and development of Leiophron pallipes Curtis (Hymenoptera: Braconidae, Euphorinae) in five mirid hosts in the Belleville district. — Proc. Entomol. Soc. Ont. 95:115-121.

Loan, C. C. \& Bilewicz-Pawińska, T. 1973: Systematics and biology of four Polish species of Peristenus Foerster (Hymenoptera: Braconidae, Euphorinae). - Environm. Entomol. 2(2):271-278.

Received 19.V.1989 